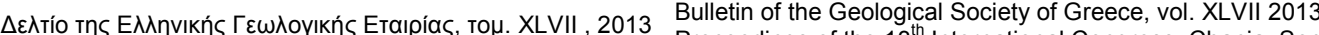
Proceedings of the $13^{\text {th }}$ International Congress, Chania, Sept.

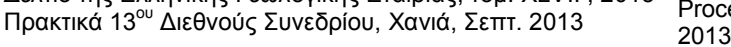

\title{
BASIN AND LOCAL SCALE DETECTION OF GROUND SUBSIDENCE THROUGH PERSISTENT SCATTERER INTERFEROMETRY: THE ANTHEMOUNTAS BASIN (NORTHERN GREECE) CASE STUDY
}

\author{
Raspini F. ${ }^{1}$, Loupasakis C. ${ }^{2}$, Rozos D. ${ }^{2}$ and Moretti S. ${ }^{1}$ \\ ${ }^{1}$ Department of Earth Sciences, University of Firenze, Via La Pira, 4 - 50121, Firenze, Italy, \\ federico.raspini@unifi.it,sandro.moretti@unifi.it \\ ${ }^{2}$ Laboratory of Engineering Geology and Hydrogeology, School of Mining and Metallurgical \\ Engineering, National Technical University of Athens, 9 Iroon Polytechneiou, Athens, Greece, \\ cloupasakis@metal.ntua.gr,rozos@metal.ntua.gr
}

\begin{abstract}
In the framework of the Terrafirma Extension project, a study has been established for ground motion detection and mapping in the Anthemountas basin (Central Macedonia). Terrafirma promotes the exploitation of Persistent Scatterer Interferometry (PSI) techniques, a remote sensing technology based on multi-temporal satellite Synthetic Aperture Radar (SAR) imagery. The potential of SAR interferometry has been exploited through the innovative Wide Area Mapping approach, recently implemented by the German Space Agency (DLR) and aimed at measuring land deformation over large areas.

Interferometric results from 1995-2001 by ERS1/2 satellites has been analyzed at a basin scale to investigate spatial patterns of land motion in the wider Anthemountas plain, where subsidence phenomena related to intense groundwater extraction is clearly manifested.

The WAP results turned out to be a valuable tool for the characterization at local scale of the land subsidence in the runaways area of the Macedonia airport and in the village of Perea, affected in 2005-2006 by a series of tensile ground ruptures due to excessive groundwater withdrawal.

Besides the study of the phenomenon, this work confirmed the suitability of PSI techniques to detect and measure surface displacements with millimetre accuracy and also to reconstruct the deformations history of the investigated areas through displacement time series analysis.

Key words: multi-temporal satellite Synthetic Aperture Radar (SAR) imagery, intense groundwater extraction, Perea village, Macedonia airport.
\end{abstract}

\section{Пврі́⿱亠乂 $\psi \eta$}

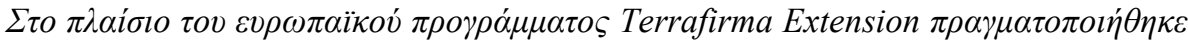

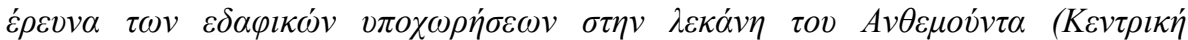

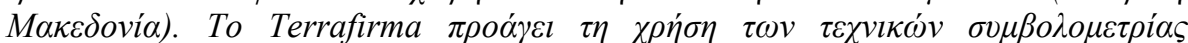
$\sigma \tau \alpha \theta \varepsilon \rho \omega \dot{v} \quad \sigma \kappa \varepsilon \delta \alpha \sigma \tau \omega \dot{v}$ (Persistent Scatterer Interferometry, PSI), $\mu l \alpha \tau \varepsilon \chi v i \kappa \eta ்$

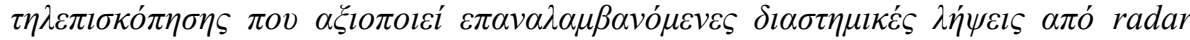

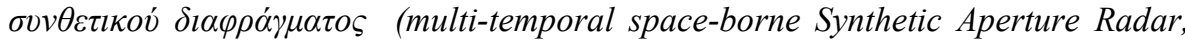

$\underline{\text { XLVII, No } 3-1510}$ 


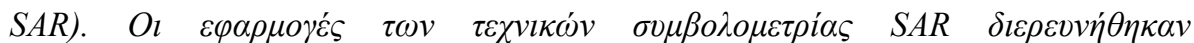

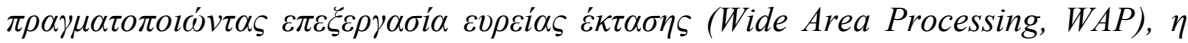
олоі́

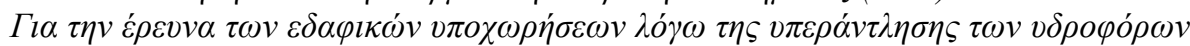

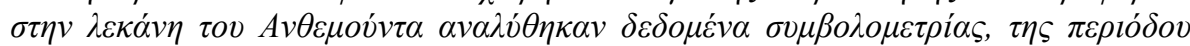

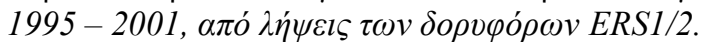

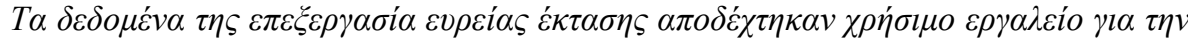

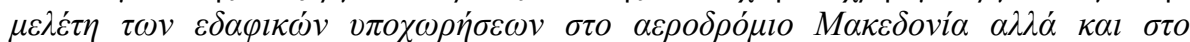

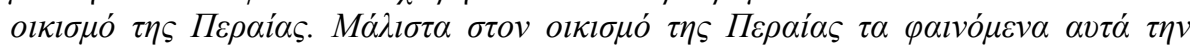

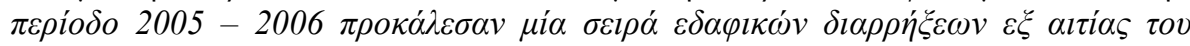

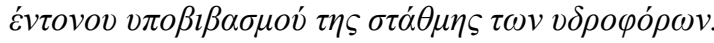

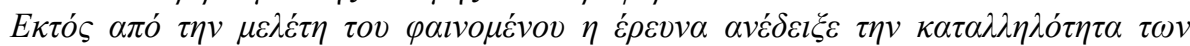

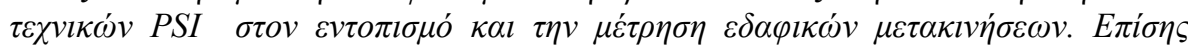

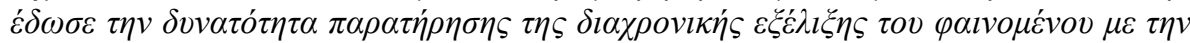

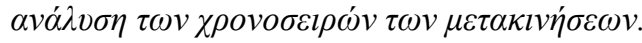

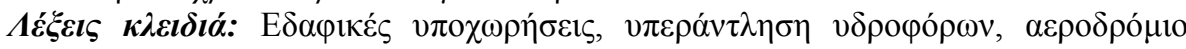

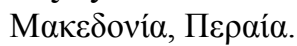

\section{Introduction}

At both regional and local scale studies satellite SAR (Synthetic Aperture Radar) interferometry has demonstrated its suitability to measure the spatial extent and magnitude of surface deformation associated with aquifer-system compaction (Galloway \& Burbey, 2011). Furthermore, its complementarity with in situ measurements and geotechnical modelling provides substantial benefits.

The exploitation of Persistent Scatterer (PS) techniques has been recently promoted by several European initiatives, such as the Terrafirma project, a pan-European ground motion hazard information service supported by the ESA's (European Space Agency) GMES (Global Monitoring for Environment and Security) programme. Since the first two-year Stage 1 (which started in 2003), the project is based upon advanced interferometry products.

Launched in December 2009, Terrafirma Extension focuses on several thematic lines for terrain motion analysis: Tectonics, Flooding, Hydrogeology (ground water, landslides and inactive mines) and the innovative Wide Area service, aimed at measuring land deformation over very large areas. Terrafirma Stage 3 consortium is led by Altamira Information, with the Dutch Geological Survey leading the Flood Theme, the Italian National Institute of Geophysics and Volcanology leading the Tectonics Theme, the University of Firenze leading the Hydrogeology Theme, and the German Space Agency leading the Wide Area Mapping task.

Within the Terrafirma project collaboration between the Earth Science Department of the University of Firenze and the Laboratory of Engineering Geology and Hydrogeology of the School of Mining and Metallurgical Engineering of the National Technical University of Athens has been established. One of the main purposes of this study is to investigate ground motions in the Anthemountas basin, a region with a relatively short history of ground subsidence. This area draw the attention of the geo-scientists in 2005 when a series of fractures, causing damages to both buildings and roads, occurred at the Perea village, on the southern section of the basin's coastal zone. These fractures were attributed to the overexploitation of the aquifers (koumantakis et al, 2008), although they manifested along the active Anthemountas Fault. The application of satellite SAR interferometry (InSAR) for the detection of land motion phenomena reviled that beside the Perea village big parts of the coastal zone subside. The main objectives of the current work are to identify the main causes of the observed ground deformations, to study their mechanisms and to validate the contribution of the remote sensing data on the study of the phenomena.

XLVII, No $3-1511$ 


\section{The Study Area}

Anthemountas basin is located on the eastern side of Thessaloniki, named after the homonymous river. It extends with a NW-SE orientation from the Thermaikos gulf to the centre of the Chalkidiki peninsula (Figure 1).

The geological formations constituting the Anthemountas basin can be distinguished on the Mesozoic bedrock formations, occupying the bordering mountains, the Neogene deposits outcropping at the hilly areas and the foot of the mountains and the Quaternary deposits occupying the plain area (IGME, 1966; 1978a; b; c; Rozos et al, 1998; Anastasiadis et al., 2001). The Mesozoic formations consist of metamorphic (phyllite and gneiss with marble intercalations) and igneous (granite, gabbro and peridotite) rocks. The Neogene deposits consist of two sequences, the upper sand and gravel sequence and the lower sandy marls - red clays sequence, outcropping successively along the borders of the basin. The quaternary formations occupy the central part of the plain, with an increasing thickness towards the coastal area (Figure 1).

Considering the aquifers three systems can be distinguished in the abovementioned formations (Nagoulis \& Loupasakis, 2001): a) the shallow phreatic aquifers system occupying the upper coarse-grained Quaternary deposits extending to a maximum depth of $30 \mathrm{~m}$, b) the semi-confined alternating aquifers, extending down to depths from 50 to more than $200 \mathrm{~m}$, occupying the lower Quaternary and the Neogene deposits as well as the fractured Mesozoic formations and c) Two deep confined (artesian) aquifers, the one gushing out at the Souroti spring (sub-acidic sparkling mineral water rich in calcium and magnesium) and the other at the thermal springs of Thermi. These systems do not seem to be affected by the ground water level variations of the two shallower aquifer systems.

The Anthemountas River basin has experienced both an increasing urbanization trend and significant population growth in the last few decades. Between 1991 and 2001 the municipality of Thermaikos, Vasilika and Anthemountas experienced an increase of population of about $108.3 \%$, $34 \%$ and 3.44\%, respectively (WATERinCORE, 2011). In the last decades, several industries, economic activities and infrastructures have developed around the Thessaloniki International Airport, one of the most important infrastructures of Northern Greece.

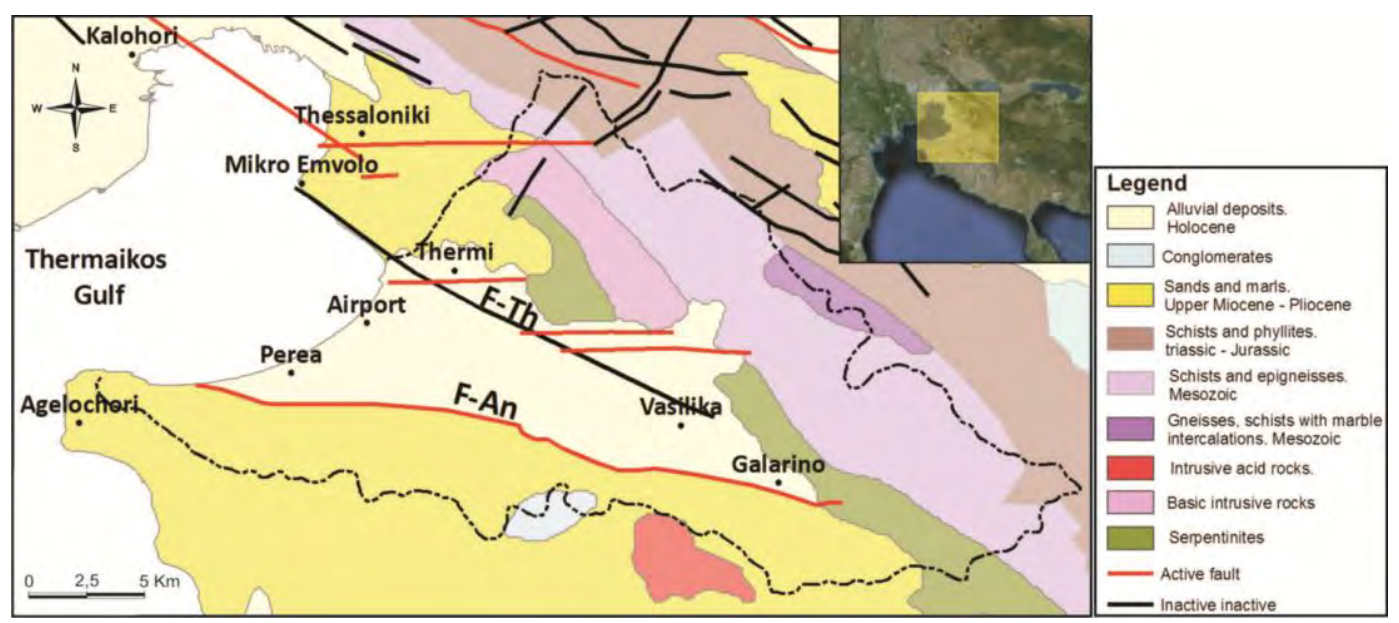

Figure 1 - Geological map of the wider study area (IGME, 1978). The abbreviations F-Th and F-An indicate the Thermi and the Anthemounta faults, respectively. The dotted line indicates the watershed line of the Anthemounta basin. 
The continuously increasing demands on water are exclusively covered by the ground water exploitation. Despite the public network for water supply and distribution, several independent and usually uncontrolled water wells have been drilled, whose water abstraction is neither controlled nor systematically metered. Groundwater resources have been considered as renewable and unlimited and no attention was paid on their management. This resulted in the over-exploitation of the phreatic and the semi-confined aquifers, the decline of water levels with a mean annual rate of $1,5-2 \mathrm{~m}$ and, finally, in the the loss of aquifers storage capacity.

\section{Land Subsidence Evolution}

\subsection{Field Observations}

The land subsidence phenomena draw the attention of the geo-scientists in 2005 when a series of fractures damaged at the upper Perea village. The fractures caused damages to both buildings and roads extending at a length of about one kilometre (Figure 2). The fractures occurred along the active Anthemounta fault confusing the scientific community. Finally, the phenomenon was attributed to the local overexploitation of the aquifers as in short distance, only a few tens of meters away, three public wells and an unknown number of private wells were operating (Koumantakis et al., 2008). So, the operating wells with a $2,2 \mathrm{~m}$ mean annual drawdown rate generated an extra drawdown and inside the limits of the intersecting depression cones of the wells the raptures occur.

Apart from the tensile ruptures other visible traces of subsidence, like well-casing protrusion (Figure 3), has been reported northern to surface ruptures, at the same time period. Note that, no other effects related to the groundwater withdrawal can be clearly detected since 2005, not only at the narrow Perea village region but also at the entire basin.

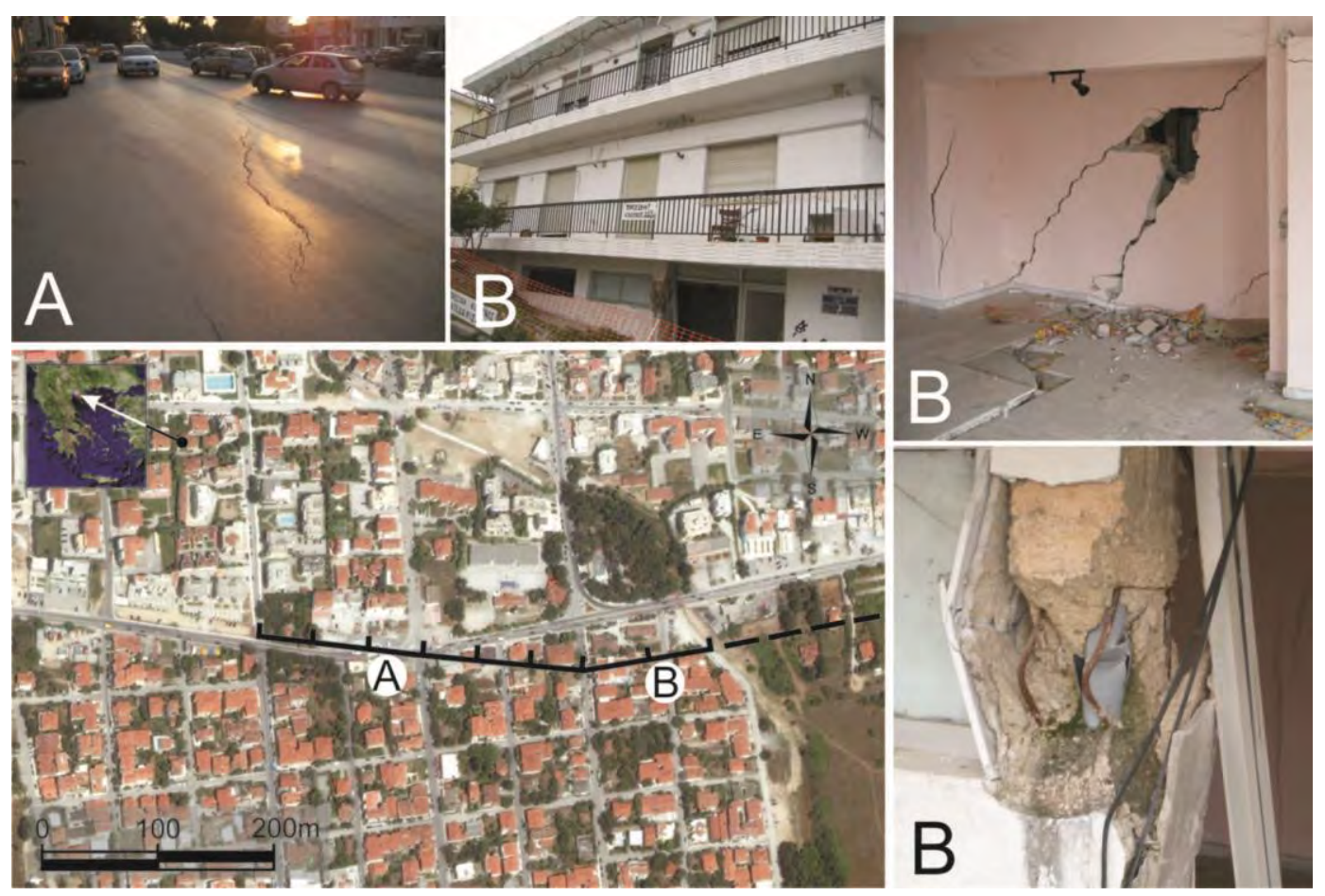

Figure 2 - Satellite picture indicating the 2005 ground rupture in upper Perea. The attached pictures present the damages witnessed at the road paving (A) and at the buildings (B).

$\underline{\text { XLVII, No } 3-1513}$ 


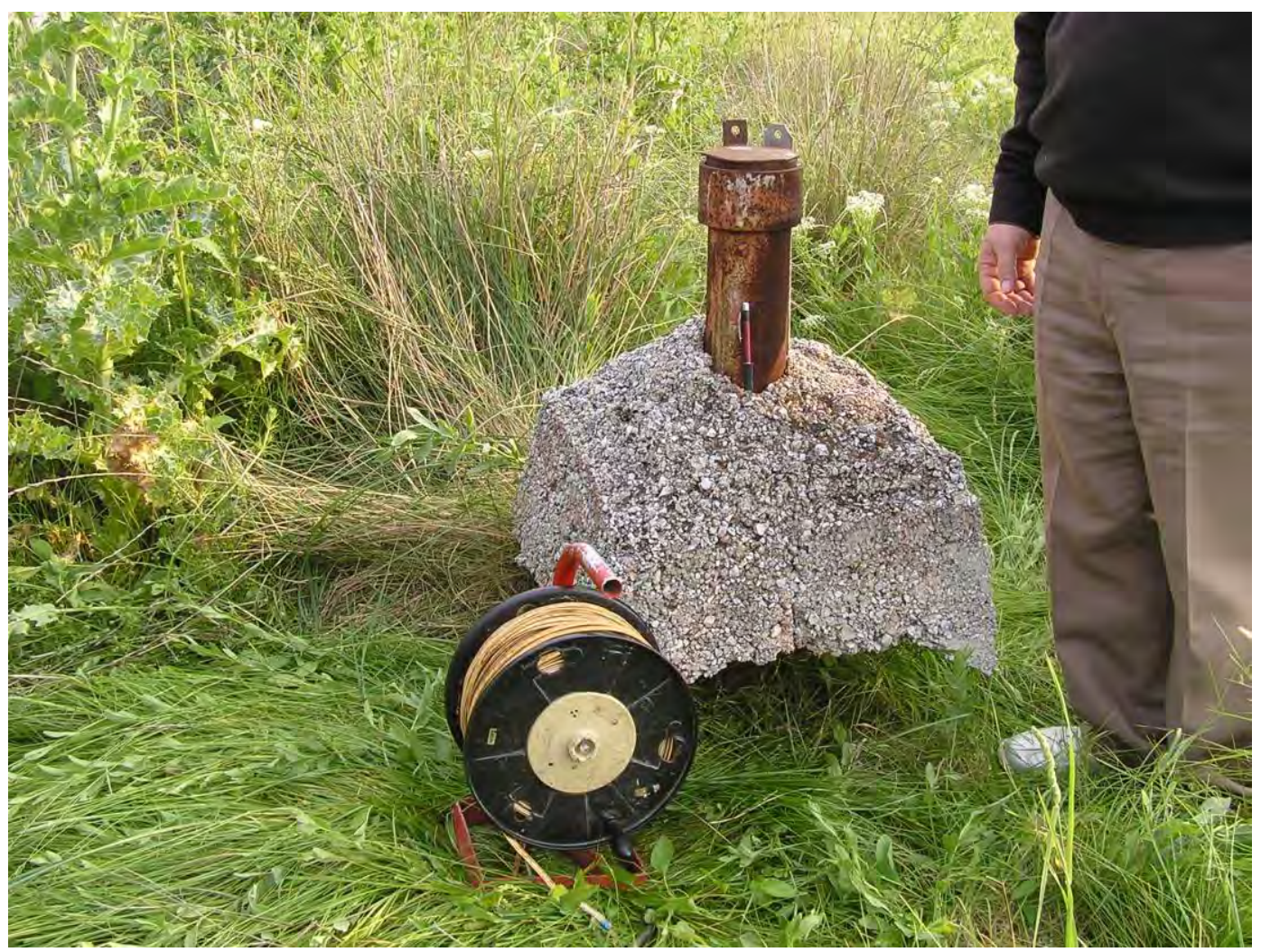

Figure 3 - Well-casing protrusion, of about $20 \mathrm{~cm}$. The current well is located next to the $G 2$ main well (Figure 6).

\subsection{The PSI Interferometric Technique}

The land subsidence phenomenon in the wider Anthemountas Plain was studied by exploiting the PSI technique, a remote sensing technology based on multi-temporal satellite SAR (Synthetic Aperture Radar) imagery. The PSI (Persistent Scatterer Interferometry) techniques are based on the processing of several multi-temporal satellite SAR imagery (at least 15-20, or more) of the same target area. The current technique uses long stacks of radar dataset and analyzes the signals backscattered from the observed scene aiming to estimate and remove atmospheric artifacts (Adam et al., 2011). The electromagnetic returns of electromagnetically stable, highly reflective pointwise targets (the so-called Permanent Scatterers, (PS) is statistically processed and analyzed to retrieve estimates of the displacements occurred between different acquisitions (Ferretti et al., 2000 ; 2011). PSs usually correspond to manmade structures (i.e. buildings, roads, bridge, monuments, pylons), as well as natural reflectors, such as outcropping rocks. Thanks to this multiinterferometric approach the LOS velocity can be estimated, at each Permanent Scatterer, with unprecedented accuracy, sometimes even better than $0.1 \mathrm{~mm} /$ year. Displacement time series can be retrieved, acquisition by acquisition, with accuracy on single measurements usually ranging from 1 to $3 \mathrm{~mm}$ (Colesanti et al., 2003). Each measurement is temporally and spatially referred to a unique reference image and to a stable reference point, respectively.

\subsection{SAR Data Used}

In the framework of the ESA GMES Terrafirma project, a Wide Area Product (WAP) mapping, based on PSI, was demonstrated by the German Space Agency (DLR). Specifically, 9 satellite image frames were processed using a special semi-automated processor to produce a PSI ground motion map covering a $65,000 \mathrm{~km}^{2}$ wide area of Greece. This WAP (Wide Area Product) mapping 
over Greece is based on stripmap ERS1/2 images, obtained from the European Space Agency (ESA). Among these 9 satellite image frames, track 7_3 was employed for the reconstruction of the history and spatial patterns of land subsidence in the wider Anthemountas area. Track 7_3 consists of a dataset of 42 SAR imagery in $\mathrm{C}$ band (5.6 $\mathrm{cm}$ wavelength), acquired along descending orbits from April 1995 to January 2001.

The reference points of the stack - to which the displacement estimates are referred - was selected in the southernmost part of Thessaloniki's urban fabric, in a sector unaffected by ground motions. The master image for Track 7 _ 3 dataset has been chosen on December 31st, 1996.

\subsection{Evaluation of the PSI Data}

The analysis of the mean annual displacement velocities, retrieved by PSI processing, provides essential information. An overview of the WAP results for wider Anthemounta basin is presented in Figure 4, as measured by the SAR sensor along the satellite's line of sight and expressed in $\mathrm{mm} / \mathrm{y}$. The green dots refer to stable areas. The red dots represent increasing deformation rates, moving away from the sensor (subsidence). As expected, the density of measurement points is higher for the urban areas (maximum density up to about $300 \mathrm{PS} / \mathrm{km}^{2}$ ), but lower for agricultural and vegetated terrains (few point $/ \mathrm{km}^{2}$ ).

The PSI results reveal that the city of Thessaloniki shows very low LOS deformation rates, ranging between -1.5 and $1.5 \mathrm{~mm} / \mathrm{yr}$ (close to the PSI technique detection sensitivity), indicating stable ground conditions. Considering that a large part of the urban fabric is built over Neogene formations the above observation is reasonable. On the contrary the coastal area of the Anthemountas basin presents significant deformations (Figure 4).

Land subsidence can be clearly identified in the wide Anthemountas basin area with a mean deformation rate of $10 \mathrm{~mm} / \mathrm{yr}$ (Figure 4). In the airport area, observed LOS subsidence rates are 5$15 \mathrm{~mm} / \mathrm{yr}$, with several points exceeding $20 \mathrm{~mm} / \mathrm{yr}$ along the NNW-SSE oriented runaway area (Figure 5). PSI results reveal that the coastal area of the Perea village shows very low LOS deformation rates, ranging between -1.5 and $1.5 \mathrm{~mm} / \mathrm{yr}$, indicating relatively stable ground conditions since 1995. Nevertheless, in the southern part of the urban area subsidence can be observed, with maximum LOS deformation rates up to $10-15 \mathrm{~mm} / \mathrm{yr}$ (Figure 6). The fact that the deformations have not affected the lower Perea as well supports the theory claiming that they were caused by the local overexploitation of the aquifers inside the intersecting depression cones of the active wells.

It is worth to notice that detected subsiding areas in the wider Anthemountas basin are distributed as either circular or as elongate patterns. The main "classical" subsidence bowl, corresponding to intense groundwater extraction, affects mostly the central part of the basin: here the measured subsidence rates seem to increase towards the coastline, where the thickest sequences of compressible Quaternary layers crop out.

Furthermore, a NW-SE oriented pattern, elongated parallel to the major normal Thermi fault (F-Th in Figure 1) bordering the NE part of the basin can be observed. This fault marks the geological boundary between the Quaternary alluvial sediments on the hanging wall and the Neogene over consolidated formations. According to the PSI data along the fault line a mean deformation of 5-7 $\mathrm{mm} / \mathrm{yr}$, with peak values up to $10 \mathrm{~mm} / \mathrm{yr}$, is observed. These activity indications are of great interest as up to now this fault is referred to as inactive (Pavlides \& Kilias, 1987; Tranos et. al., 1999, 2003; Zervopoulou, 2010). The lack of data across the fault prevent the calculation of the actual differential displacement across the fault, so the absolute deformation values deriving from the analysis $(5-7 \mathrm{~mm} / \mathrm{yr})$ seems to be excessive and they cannot be taken under consideration. In that case the PSI date can be considered only as activity indications. 


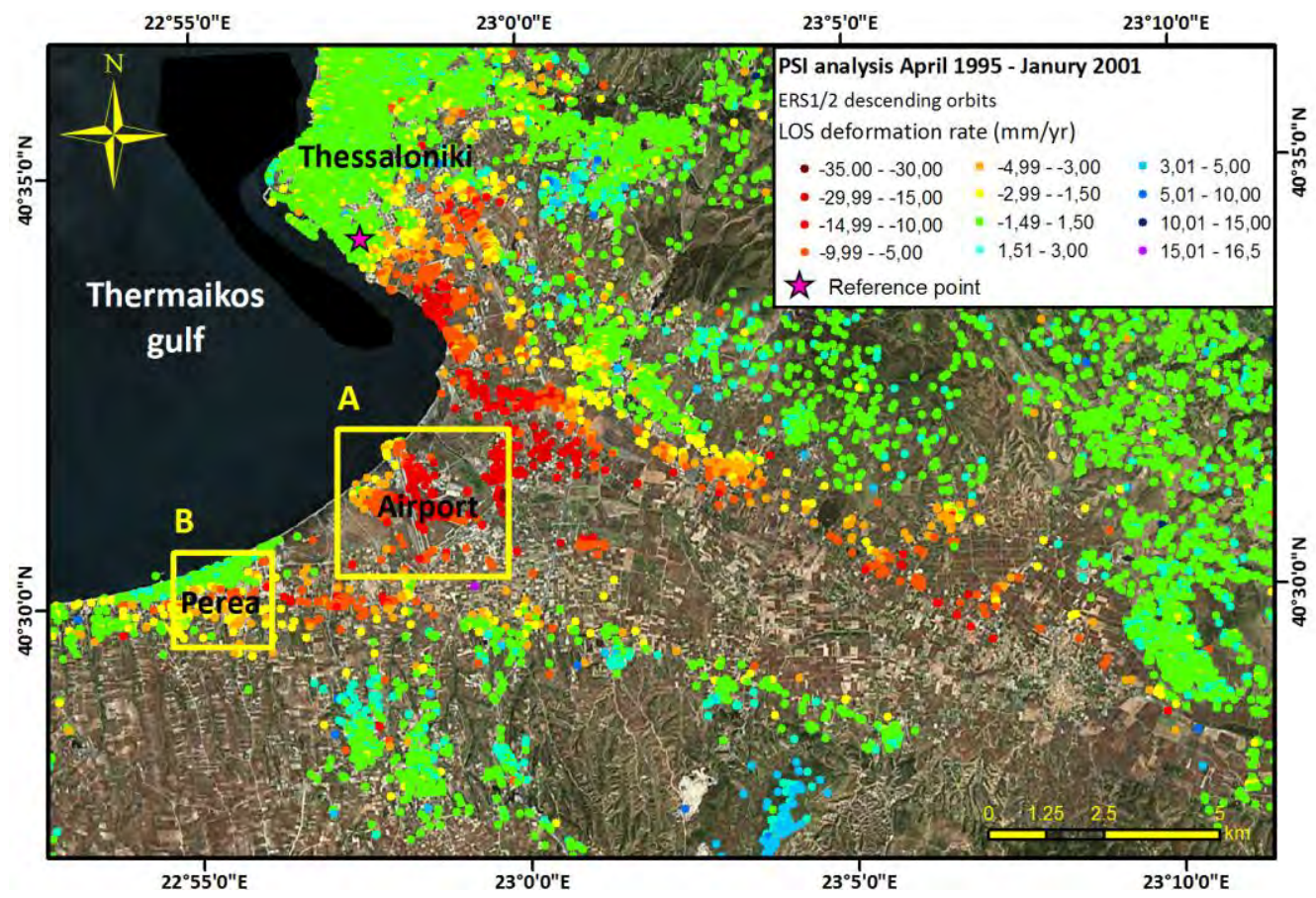

Figure 4 - Basin scale detection of ground subsidence through PSI. The Line of Sight - LOS deformation rates in the Anthemountas basin are presented. PSI map is overlaid on Visual Earth imagery. The polygons $A$ and $B$ indicate the areas subjected to local scale detection of ground subsidence.

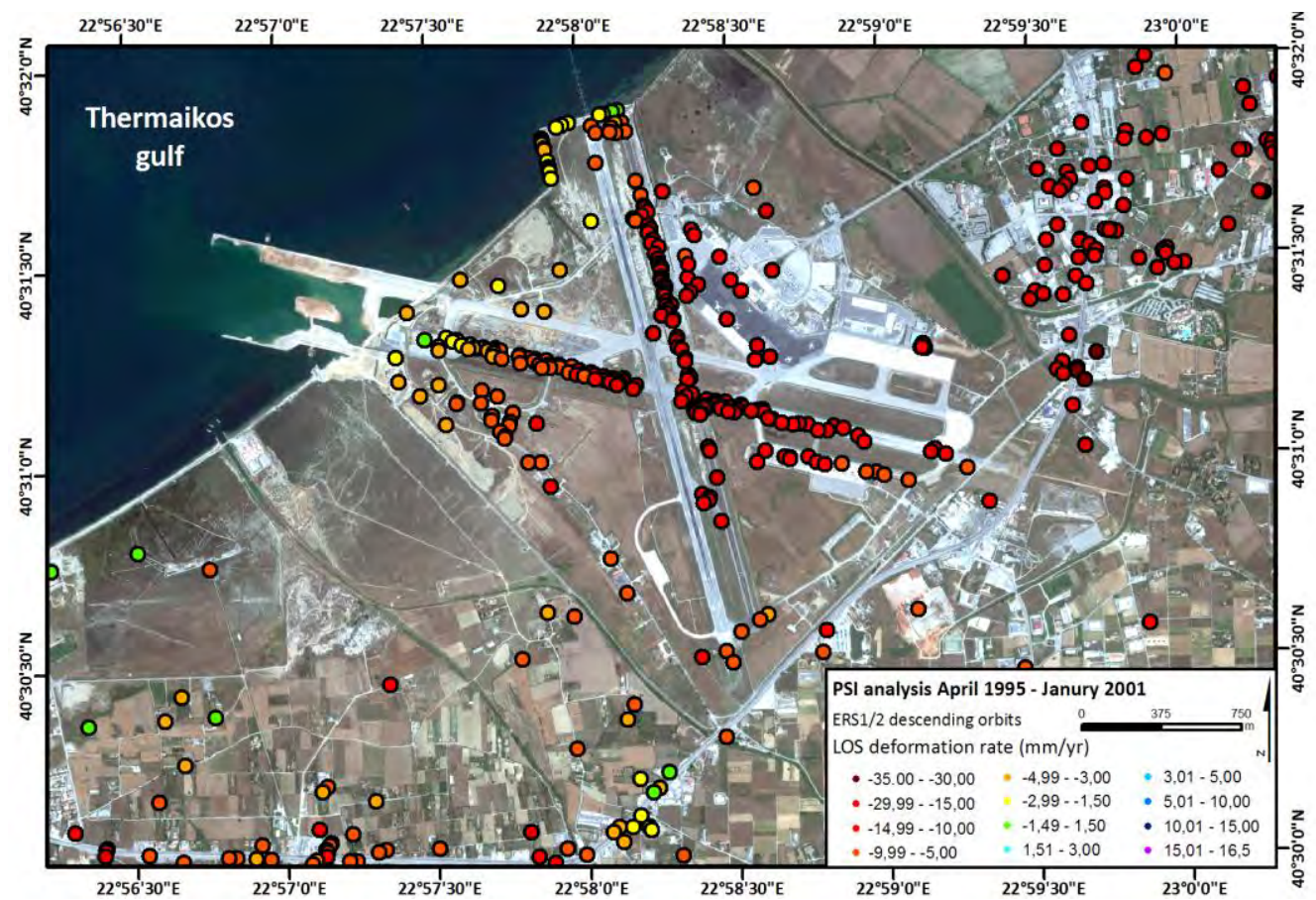

Figure 5 - Local scale detection of ground subsidence through PSI at the Macedonia International Airport. The location of the airport is clearly indicated in Figure 4. 


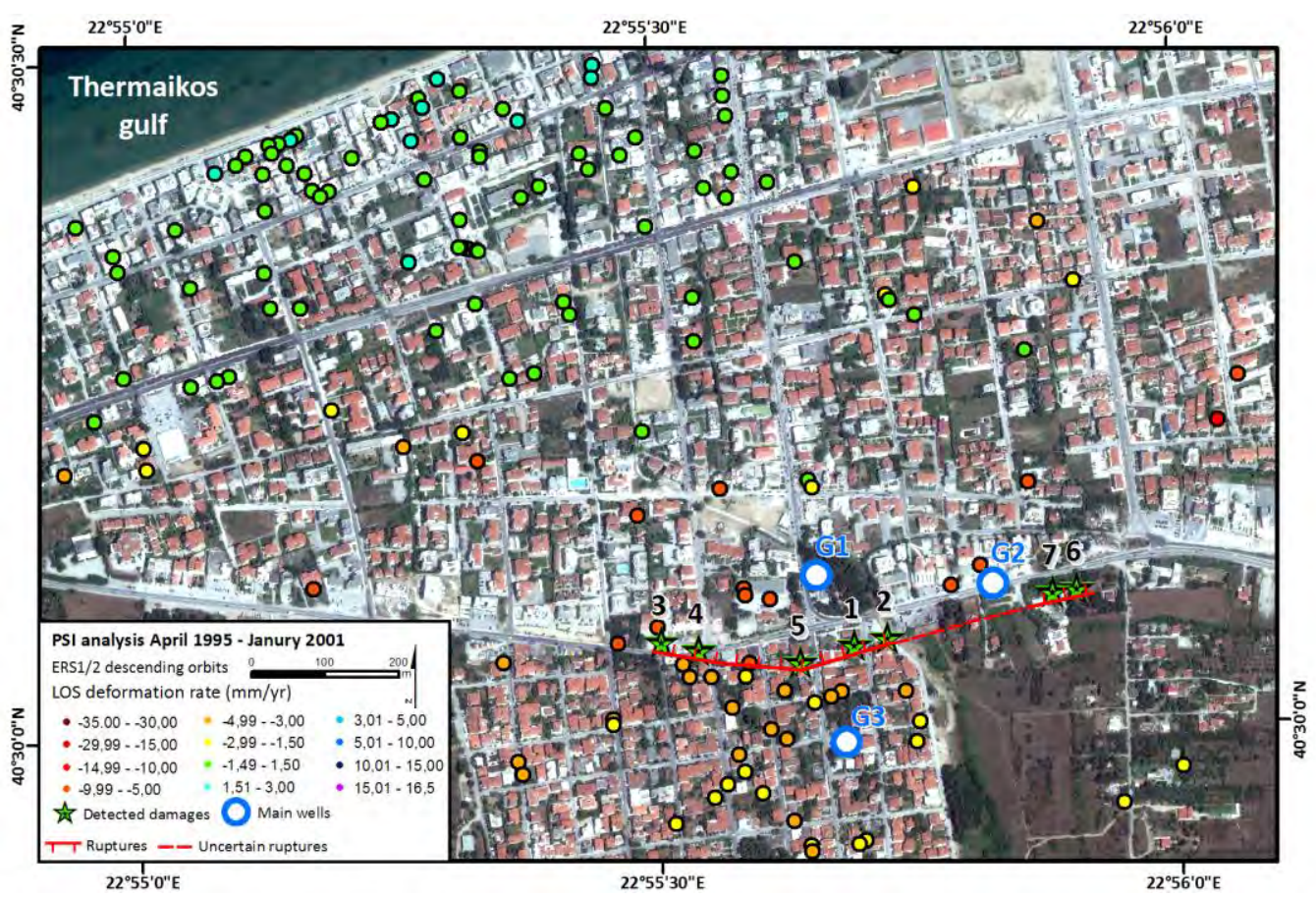

Figure 6 - Local scale detection of ground subsidence through PSI at the Perea Village. The location of the village is clearly indicated in Figure 4.

\section{Conclusions}

The PSI results provided substantial information about the actual extent of the land subsidence phenomenon as, up to now, the only indications of this phenomenon were identified at the village of Perea. As already mentioned the Perea village was affected in 2005-2006 by a series of ground ruptures triggered by the excessive groundwater withdrawal, since then no further indications about the evolution of the phenomenon were recorded. The PSI data revealed that not only Perea but also the entire lower part of the Anthemountas plain area is affected by land subsidence phenomena. The most affected area includes a big part of the Thermi industrial zone as well as the Macedonia international airport.

The detection of the phenomena at an initial stage is extremely important, as further extension of the affected area and damages on settlements and infrastructure can be prevented. The information provided by this study can give rise to focused geotechnical and hydrogeological studies aiming to stop the phenomenon before it becomes an actual problem for the area.

This study proved that the repeat-pass satellite SAR interferometry can be exploited not only to map the extension of affected areas at a regional (basin) level but at a local level also, as it was proved valuable for the study of the phenomenon at the narrow airport or upper Perea region. Furthermore it should be noticed that this technique can also be exploited for the evaluation of the deformation history. The displacement time series, available for each PS in the area of interest, are ideal suited for large-scale, spatially continuous monitoring of geohazard-related ground motion.

\section{Acknowledgments}

The Terrafirma Extension project has funded the SAR imagery processing as well as the geological interpretation presented in this paper. The project is one of the many services being supported by the Global Monitoring for Environment and Security (GMES) Service Element

$\underline{\text { XLVII, No } 3-1517}$ 
Programme, promoted and financed by the European Space Agency (ESA). The authors gratefully acknowledge the German Aerospace Centre (DLR) for having processed the SAR data.

\section{References}

Adam N., Rodriguez Gonzalez F., Parizzi A. and Liebhart W. 2011. Wide area persistent scatterer Interferometry, Proceedings of IGARSS, Vancouver, Canada.

Anastasiadis A., Raptakis D. and Pitilakis K. (2001). Thessaloniki's Detailed Microzoning: Subsurface Structure as Basis for Site Response Analysis, Pure and Applied Geophysics, 158, 2597-2633.

Colesanti C., Ferretti A., Prati C. and Rocca F. 2003. Monitoring landslides and tectonic motion with the Permanent Scatterers technique, Engineering Geology, 68(1-2), 3-14.

Ferretti A., Fumagalli A., Novali F., Prati C., Rocca F. and Rucci A. 2011. A new algorithm for processing interferometric data-stacks: SqueeSAR ${ }^{\mathrm{TM}}$, IEEE Transactions on Geoscience and Remote Sensing, (99), 1-11.

Ferretti A., Prati C. and Rocca F. 2000. Nonlinear subsidence rate estimation using Permanent Scatterers in differential SAR interferometry, IEEE Transactions on Geoscience and Remote Sensing, 38 (5), 2202- 2212.

Galloway D.L. and Burbey T.J. 2011. Review: regional land subsidence accompanying groundwater extraction, Hydrogeology Journal (19), 1459-1486.

I.G.M.E 1966. Geological Map of Greece, Scale 1:50.000, Epanomi Sheet, IGME, Athens.

I.G.M.E 1978a. Geological Map of Greece, Scale 1:50.000, Thessaloniki Sheet, IGME, Athens.

I.G.M.E 1978b. Geological Map of Greece, Scale 1:50.000, Thermi Sheet, IGME, Athens.

I.G.M.E 1978c. Geological Map of Greece, Scale 1:50.000, Vasilika Sheet, IGME, Athens.

I.G.M.E 1978d. Geological Map of Greece, Scale 1:500.000, IGME, Athens.

Koumantakis I., Rozos D. and Markantonis K. 2008. Ground subsidence in Thermaikos municipality of Thessaloniki County, Greece. International Conference Gro-Pro - Ground water protection - Plans and Implementation in a North European Perspective, (1), 177-184 Korsør Denmark.

Nagoulis A. and Loupasakis C. 2001. Hydrogeological conditions of the plain area of the Anthemounta basin (Macedonia, Greece), Bulletin of the Geological Society of Greece, (34), $1859-1868$.

Pavlides S.B. and Kilias A.A. 1987. Neotectonic and active faults along the Serbomacedonian zone (Chalkidiki, N. Greece), Annales Tectonicae, (1), 97-104.

Rozos D., Hatzinakos I. and Apostolidis E. 1998. Engineering Geological Map of Thessaloniki wider area, Scale 1:25.000. I.G.M.E., Athens.

Tranos M.D., Kilias A.A. and Mountrakis D.M. 1999. Geometry and kinematics of the Tertiary post-metamorphic Circum Rhodope Belt Thrust System (CRBTS), Northern Greece, Bulletin of Geological Society of Greece, (33), 5-16.

Tranos M.D., Papadimitriou E.E. and Kilias A.A. 2003. Thessaloniki-Gerakarou Fault Zone (TGFZ): the western extension of the 1978 Thessaloniki earthquake fault (Northern Greece) and seismic hazard assessment, Journal of Structural Geology, (25), 2109-2123.

WATERinCORE 2011. Sustainable Water Management through Common Responsibility enhancement in Mediterranean River Basins - Strategic Water Management Plan for Anthemountas River Basin.

Zervopoulou A. 2010. Neotectonic Faults of the Wide Area of Thessaloniki in association with foundation Soils, Ph.D. Thesis, University of Thessaloniki (in Greek). 